Canadian

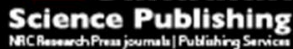

Canadian Geotechnical Journal Revue canadienne de géotechnique

The use of pore pressure build-up as damage metric in computation of equivalent number of uniform strain cycles

\begin{tabular}{|r|l|}
\hline Journal: & Canadian Geotechnical Journal \\
\hline Manuscript ID & cgj-2017-0231.R1 \\
\hline Manuscript Type: & Article \\
\hline Date Submitted by the Author: & 03-Aug-2017 \\
\hline Complete List of Authors: & $\begin{array}{l}\text { Khashila, Marwan; Universite de Sherbrooke, Civil engineering } \\
\text { Hussien, Mahmoud; Assiut University, Civil Engineering; Sherbrooke } \\
\text { University, Civil Engineering } \\
\text { Karray, Mourad; Universite de Sherbrooke, Génie Civil } \\
\text { Chekired, Mohamed; Institut de recherche d'hydro-Québec, }\end{array}$ \\
\hline Keyword: & TxSS, Liquefaction, Strain-Controlled, Ru, Pore water pressure \\
\hline & \\
\hline
\end{tabular}

SCHOLARONE ${ }^{m}$

Manuscripts 


\title{
The use of pore pressure build-up as damage metric in computation of equivalent number of uniform strain cycles
}

\author{
Marwan Khashila ${ }^{1}$, Mahmoud N. Hussien ${ }^{1,2}$, Mourad Karray ${ }^{1}$, Mohamed Chekired ${ }^{3}$ \\ ${ }^{1}$ Department of Civil Engineering, Faculty of Engineering, Sherbrooke University, Sherbrooke, QC, Canada \\ ${ }^{2}$ Department of Civil Engineering, Faculty of Engineering, Assiut University, Assiut, Egypt, \\ ${ }^{3}$ Hydro-Québec, Montréal, QC, Canada \\ Marwan Khashila \\ PhD student, Department of Civil Engineering, Université de Sherbrooke, Sherbrooke (Québec) J1K 2R1, \\ Canada \\ E-mail: Marwan.Khashila@usherbrooke.ca \\ Mahmoud N. Hussien, Ph.D. \\ Researcher, Department of Civil Engineering, Université de Sherbrooke, Sherbrooke (Québec) J1K 2R1, \\ Canada \\ Tel.: (819) 821-8000 (61034) \\ E-mail: Mahmoud.Nasser.Ahmed@USherbrooke.ca \\ Mourad Karray. ing., Ph.D. (corresponding author) \\ Professor, Department of Civil Engineering, Université de Sherbrooke, Sherbrooke (Québec) J1K 2R1, \\ Canada \\ Tel.: (819) 821-8000 (62120) \\ Fax: (819) 821-7974 \\ E-mail: Mourad.Karray@,Usherbrooke.ca \\ Mohamed Chekired. ing., Ph.D. \\ Researcher, Institut de Recherche d'Hydro-Québec, Varennes (Québec) J3X 1S1, Canada \\ Tel.: (450) 652-8289 \\ E-mail: $\underline{\text { Chekired.Mohamed@ireq.ca }}$
}




\begin{abstract}
The build-up of earthquake-induced excess pore water pressure may be viewed as analogous to the cumulative damage of saturated granular materials caused by cyclic loading, and consequently as damage metric when converting an irregular earthquake loading to an equivalent number of uniform cycles, $N_{e q}$. In this paper, a comprehensive series of strain-controlled tests have been conducted using the new combined triaxial simple shear $\left(\mathrm{T}_{\mathrm{x}} \mathrm{SS}\right)$ apparatus developed at IREQ in collaboration with the Geotechnical group at the Université de Sherbrooke to verify the hypothesis of adopting the pore water pressure ratio $R_{u}$, as damage metric when converting earthquakes to an equivalently damaging number of uniform strain cycles. Different reconstituted saturated samples of Baie-Saint-Paul, Carignon, and Quebec sands have been tested under undrained condition up to liquefaction. The experimental results from this study have been utilized to develop an empirical expression to compute $N_{e q \gamma}$ from both the number of cycles required to trigger liquefaction $N_{l i q}$, and the material parameter $r$. The parameter $r$, had been experimentally calibrated a priori from a separate set of tests using uniform strain cycles following the theoretical framework outlined by Green and Lee (2006). The present results reveal that the measured pore water pressure ratio $R_{u}$, is in accord with predicted cumulative damage using the R$\mathrm{N}$ hypothesis. However, the P-M hypothesis underestimates the cumulative damage (i.e., the generated pore water pressure) during cyclic loading.
\end{abstract}

Keywords: Liquefaction; pore water pressure ratio; number of equivalent cycles; Triaxial simple shear apparatus; cumulative damage.

\title{
Introduction
}

Liquefaction of saturated sand deposits under seismic loading is one of the most important damaging phenomena in soil dynamics that can be regarded as a special case of soil fatigue failure resulted from the gradual build-up of excess pore water pressure accompanied by the accumulative loss of strength and stiffness. Over the last several decades, numerous experimental (e.g., Silver and Park 1976; Rahman et al. 2014) and field (e.g., Seed et al. 1983; Juang et al. 2003) investigations have been carried out aiming to grasp a close understanding of liquefaction phenomenon and to develop reliable procedures to evaluate its potential occurrence in the field. Among these procedures, the simplified procedure developed from empirical evaluations of field and laboratory test data by prof. H. B. Seed and his colleagues at the University of California at Berkeley stands as the most widely used procedure. In this procedure, laboratory testing on soil samples subjected to uniform shear stress (i.e., stress- 
controlled cyclic test) with continuous monitoring of pore water pressure build-up (undrained tests) or volume change (drained tests) is utilized to construct the soil cyclic loading strength $\left(C S R-N_{l i q}\right)$ curves, where the $C S R$ represents the cyclic stress ratio required to generate liquefaction and $N_{\text {liq }}$ represents the corresponding number of cycles (Seed and Idriss 1971). However, applying this procedure intuitively required the conversion of the irregular earthquake motion measured in the field to an equivalent number of uniform stress $\left(N_{\text {eq }}\right)$ cycles. In fact, Seed et al. (1975a) applied minor modifications to the well-known Palmgren-Miner (P-M) hypothesis (Palmgren 1924; Miner 1945), originally proposed for metal fatigue analyses, to compute $N_{\text {eq }}$ for evaluating the soil liquefaction potentials. Based on Seed et al. procedure, an intensive research work has been done to correlate $N_{\text {eq }}$ of earthquake ground motion to facilitate the assessment of liquefaction potential (e.g., Annaki and Lee 1977; Liu et al. 2001; Lasley et al. 2017). Although Seed et al. procedure is simple, empirical, and is based on both laboratory and field observations, several authors (e.g., Silver and Park 1976; Wer and Dobry 1982; NRC 1985; Kazama et al. 2000) pointed out some limitations of the stress-controlled testing adopted in the simplified procedure. For example, the difficulty in defining the exact state at which the liquefaction initiates and the abrupt increase of the pore water pressure at higher number of cycles. The limitations of the stress-controlled test were discussed in detail in Kramer (1996) and Liu and $\mathrm{Xu}(2015)$.

Moreover, it is well known that the cyclic behavior and cyclic volume change of soils are fundamentally affected by the cyclic strain amplitude than the cyclic stress amplitude (Dobry and Vucetic 1987; Vucetic 1994). In fact, cyclic strain-controlled tests produce quite consistent and more realistic pore water pressure data because they alleviate the effect of soil fabric and sample disturbance (Silver and Seed 1971; Dobry 
et al. 1982; Dobry and Vucetic 1987; Vucetic 1994; Chang et al. 2007). For this particular reason, some researchers suggested using cyclic strain-controlled tests as a basis for the computation of the excess pore water pressures (Dobry et al. 1982; Dobry et al. 1985; Vucetic and Dobry 1988), and consequently to construct the ( $\gamma_{c y c}-$ $\left.N_{\text {liq }}\right)$ curves, where $\gamma_{c y c}$ is the shear strain amplitude required to trigger liquefaction (Talaganov 1996; Sitharam et al. 2012). The $\left(\gamma_{c y c}-N_{l i q}\right)$ curve is analogy to the wellknown $\left(C S R-N_{l i q}\right)$ curve obtained from stress-controlled liquefaction tests. The latter curve was previously adopted by Seed et al. (1975a) following the $(S-N)$ metal fatigue curve introduced by Palmgren (1924) and Miner (1945) for metal fatigue studies, where $N$ is the number of uniform stress cycles having amplitude $S$ required to cause a specific degree of strength deterioration of metal component (Annaki and Lee 1977). To assess soil liquefaction potential, using strain-controlled tests, it is also required to convert an irregular earthquake motion to a uniform strain $\left(N_{\text {eq }}\right)$ cycles. Tokimatsu and Seed (1987) assumed that $N_{e q \gamma}$ is equal to $N_{e q \tau}$ for an earthquake motion and

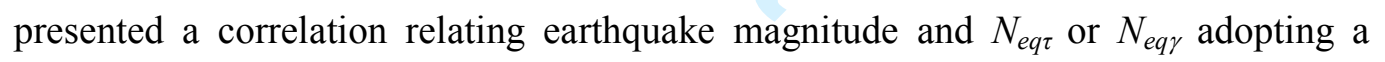
variant of the P-M hypothesis (Green and Lee 2006). Green and Lee (2006) outlined a theoretical framework supported by some practical examples for computing $N_{e q \gamma}$ adopting the incremental volumetric strain $\left(\Delta \varepsilon_{v}\right)$ model proposed by Martin et al. (1975) and its development by Byrne (1991). In their calculations, Green and Lee (2006) used both (P-M) (Palmgren 1924; Miner 1945) and (R-N) (Richart and Newmark 1945) hypotheses of material damage. They pointed out that the P-M hypothesis over-predicts $N_{\text {eqr }}$ as compared to the R-N hypothesis. Moreover, the values of the $N_{e q \gamma}$ computed by R-N hypothesis are significantly equal to $N_{e q \tau}$ computed by equating the dissipating energy approach outlined earlier by Green and 
Terri (2005). However, their theoretical work lacks a direct experimental verification for a definite conclusion with respect to the computation of $N_{\text {eq }}$ from the P-M or R-N hypotheses, which is the main objective of the current study.

In this paper, an experimental program was adopted to pursue the theoretical framework of Green and Lee (2006) by adopting the recorded pore water pressure ratio $R_{u},\left(\Delta u / \sigma_{c o}^{\prime}\right)$ in strain-controlled tests as damage metric; where, $\Delta u$ is the measured excess pore water pressure, and $\sigma_{c o}^{\prime}$ is the initial effective stress. The main purposes of this study can be summarized as: (1) to investigate the liquefaction potential under strain-controlled condition; (2) to study the use of pore water pressure as damage metric; and (3) to develop an empirical expression to compute $N_{\text {eq }}$ from both the number of cycles required to trigger liquefaction $N_{\text {liq }}$, and the material parameter $r$, experimentally calibrated a priori from a separate set of tests using uniform intensity cycles. To this end, cyclic uniform, non-uniform and irregular tests were performed in the new combined triaxial simple shear $\left(\mathrm{T}_{\mathrm{x}} \mathrm{SS}\right)$ apparatus (Chekired et al. 2015) developed at the Institut de Recherche d'Hydro-Québec (IREQ) in collaboration with the Geotechnical group at the Université de Sherbrooke.

Before describing the experimental program and the experimental results, a brief review of both the $\mathrm{P}-\mathrm{M}$ and $\mathrm{R}-\mathrm{N}$ cumulative damage theories and their application in computing equivalent number is presented to be followed by an overview of some of the existing pore pressure build-up models relevant to the study described herein.

\section{Equivalent number concept and cumulative damage: a review}

The concept of equivalent number of cycles is to convert an irregular earthquake motion to uniform strain or stress cycles having the same damage effect. It was first 
applied on metal fatigue analysis to convert non-uniform loading result from machines and traffic loads to equivalent-damage uniform loads using different cumulative damage hypotheses (Green and Terri 2005). The main advantages of the converting process are: (1) one set of laboratory test data can be used to evaluate many earthquake motions (Seed et al. 1975a); (2) it facilitates the comparison between the induced earthquake stresses in the field and the resistance obtained from cyclic uniform experimental tests.

The most widely used approach is the Palmgren-Miner ( $\mathrm{P}-\mathrm{M})$ and it is considered the basis for most engineering problems dealing with irregular loading. It was first introduced by Palmgren (1924) and further developed by Miner (1945) to predict fatigue damage $D$, of metal under a cyclic non-uniform load. However, the main limitation of the P-M hypothesis is that it is intended for high cycle fatigue conditions (i.e., large number of cycles with low amplitude). In addition, it does not consider the sequencing of peaks in earthquake time history which significantly has an influence on pore water pressure build-up in saturated soil (e.g., Martin et al. 1975; Ishihara and Nagase 1988). The main assumption of the P-M hypothesis is that the damage accumulates linearly during cyclic loading. Therefore, the relation between the cumulative damage $D$, after n cycles with constant load amplitude versus cyclic ratio $R_{n},\left(R_{n}=n / N\right.$, where, $N$ is number of failure cycles $)$ can be obtained by a unique linear relation irrespective of the load amplitude value (i.e., load independent relationship) (Green and Lee 2006). For a given time history of uniform or nonuniform load amplitude, the total fatigue damage $D$, according to the P-M hypothesis can be estimated from Eq. 1, regardless of load peak sequence (Annaki and Lee 1977). 


$$
D=\sum_{i} \frac{n_{i}}{N_{i}}
$$

where, $i$ defines each stress level; $n_{i}=$ number of cycles having peak stress amplitude $S_{i} ; N_{i}=$ number of cycles required to cause failure $(D=1)$ at the same stress intensity. The equivalent number of uniform stress $N_{\text {eq }}$, cycles having amplitude $S_{\text {ref, }}$ which has the same damage effect of an arbitrary pattern and induces failure in $N_{\text {ref }}$ cycles can be obtained following the P-M hypothesis (Annaki and Lee 1977):

$$
D=\frac{N_{e q \tau}}{N_{r e f}}=\sum_{i} \frac{n_{i}}{N_{i}}
$$

or

$$
N_{e q \tau}=N_{r e f} \sum_{i} \frac{n_{i}}{N_{i}}
$$

In the late 1960 s to the early 1970 s, Prof. Seed and his colleagues, in their intensive work at Berkeley, adopted the $\mathrm{P}-\mathrm{M}$ hypothesis to compute $N_{\text {eq } \tau}$ for evaluation of liquefaction potential (e.g., Lee and Chan 1972; Seed et al. 1975a; Annaki and Lee 1977). Green (2001) introduced adjustments to the P-M method to overcome the aforementioned shortcomings of the P-M hypothesis and to alleviate the influence of soil softening on the computed dissipated energy (Green and Terri 2005).

Based on the P-M hypothesis, Richart and Newmark (1948) developed a different cumulative damage hypothesis denoted as R-N. R-N hypothesis accounts for both the amplitudes of the peaks and their sequencing in the ground motion time history. Unlike the P-M hypothesis, the R-N hypothesis is applicable for both high and low cycle fatigue analyses. R-N hypothesis is also considered as an alternative form to the widely used model introduced by Martin et al. (1975) and Byrne (1991) procedure (Green and Lee 2006). In contrast to P-M hypothesis, R-N is load dependent hypothesis, i.e., the relation between cumulative damage $D$, after number 
of uniform stress or strain cycles $n$, versus cyclic ratio $R_{n}$, depends on load amplitude and can be obtained according to Green and Lee (2006) by:

$$
D=\left(R_{n}\right)^{r}
$$

where, $r$ is a material parameter that depends on the load amplitudes and $R_{n}$ is the cyclic ratio. For an applied cyclic stress or strain time history consists of sequent cycles of $n_{1}, n_{2}, n_{m}$ having varying peak amplitudes of $S_{1}, S_{2}, S_{m}$, the cumulative damage $D$, can be estimated after each sequent cycle by:

$$
\begin{gathered}
D_{1}=\left(\frac{n_{1}}{N_{1}}\right)^{r_{1}} \\
D_{2}=\left[\left(D_{1}\right)^{\frac{1}{r_{2}}}+\left(\frac{n_{2}}{N_{2}}\right)\right]^{r_{2}} \\
D_{m}=\left[\left(D_{m-1}\right)^{\frac{1}{r_{m}}}+\left(\frac{n_{m}}{N_{m}}\right)\right]^{r_{m}}
\end{gathered}
$$

where, $D_{1}, D_{2}, D_{m}$ is the cumulative damages induced after $n_{1}, n_{2}, n_{m}$, respectively; $N_{1}, N_{2}, N_{m}$ are number of cycles required to cause liquefaction corresponding to uniform cycles having amplitude $S_{1}, S_{2}, S_{m} ; r_{1}, r_{2}, r_{m}$ is the material parameters corresponding to amplitude $S_{1}, S_{2}, S_{m}$, respectively, where, $\mathrm{m}$ is the total number of cycles in the time history. $N_{e q}$ of uniform cycles can be computed from Eq.7 by equating the cumulative damage of earthquake time history, obtained from Eq.5, with that obtained from equivalent uniform cycles, Eq.6.

$$
\begin{gathered}
D=\left(\frac{N_{e q}}{N_{r e f}}\right)^{r_{r e f}} \\
N_{e q}=N_{r e f}\left[\left(D_{m-1}\right)^{\frac{1}{r_{m}}}+\left(\frac{n_{m}}{N_{m}}\right)\right]^{r_{m} / r_{r e f}}
\end{gathered}
$$


where, $r_{r e f}$ is the material parameter corresponding to the load amplitude $S_{r e f}$. The P-M hypothesis can be considered as a special case of the R-N hypothesis when $r=1$ for all load amplitudes. That case is occurred when the material is load independent.

\section{Pore pressure build-up models}

During earthquake loading on saturated soil, pore water pressure dissipation is not allowed as load is applied in very short time. Therefore, some of its intergranular effective stresses are transferred to pore water which leads to progressive pore water pressure build-up and a decrease of the effective stress (Seed and Lee 1966; Rahman et al. 2014). A variety of models have been developed over the years to predict pore water pressure ratio $R_{u}$, in saturated soil subjected to uniform and earthquake loading as a function of cyclic ratio $R_{n}$ (Polito et al. 2008). These early models were based on two main approaches: cyclic stress (Seed et al. 1975b) and cyclic strain approach (Martin et al. 1975) which was followed by strain energy-based model (Nemat-Nasser and Shokooh 1979).

Seed et al. (1975b) introduced the first empirical relation between pore water pressure ratio $R_{u}$, and cyclic ratio $R_{n}$, Eq. 8 , based on the experimental work done by DeAlba et al. (1975).

$$
R_{u}=\frac{1}{2}+\left[\frac{1}{\pi} \cdot \arcsin \left(2 \cdot\left(R_{n}\right)^{\frac{1}{\alpha}}-1\right)\right]
$$

Where, $\alpha$ is an empirical constant which depends on the soil properties and test conditions (Polito et al. 2008). The $R_{u}$ from Eq.8 was adopted by Wer and Dobry (1982) as damage metric to compute $N_{\text {eqq. }}$. The advantage of this procedure is that it considers the consequence effect of each half cycle in the time history on pore water pressure build-up. However, its limitations are, it depends on numerical pore pressure model in addition to the difficulty of defining the exact value for $\alpha$. According to 
Polito et al. (2008), the value of $\alpha$ is a function of fine content $(F C)$, relative density $\left(D_{r}\right)$, and cyclic stress ratio $(C S R)$ and cannot be assumed equal to 0.7 for all cases. In the current study, the pore water pressure measured in the $\mathrm{T}_{\mathrm{x}} \mathrm{SS}$ apparatus during applying earthquake time history is directly used as damage metric to compute $N_{e q \gamma}$ by equating the generated pore water pressure ratio by that generated by $N_{e q \gamma}$ of uniform strain cycles. On the other hand, the use of pore water pressure build-up in saturated soil as damage metric to compute $N_{e q}$ is generally not recommended by several researches, particularly, with strong ground motions (Haldar and Hochaimi 1984). They attributed their recommendation to the fact that the $R_{u}$ may exceed the unity prior to the end of shaking in major earthquakes; therefore the subsequent motions do not contribute in computing $N_{e q}$ (Carter et al. 2013). However, cases where $R_{u}$ exceeds the unity are out of the scope of the current study. The current study, in fact, focuses chiefly on pore water pressure build-up up to liquefaction (i.e., $R_{u}=0.9$ ).

\section{Experimental work}

\section{Testing apparatus}

The Combined Triaxial Simple Shear, $\mathrm{T}_{\mathrm{x}} \mathrm{SS}$ apparatus (Chekired et al. 2015) developed at the Institut de Recherche d'Hydro-Québec (IREQ) in collaboration with the Geotechnical group at the Université de Sherbrooke was used in the current study. The $T_{x} S S$ was designed to perform simple shear stresses on soil specimen in triaxial condition under strain-controlled drained or undrained conditions. The apparatus allows saturating and consolidating the soil specimen under hydrostatic confining pressure in triaxial chamber. In addition, it allows performing tests on reconstituted and intact soil samples under isotropic or anisotropic condition. It has the ability to host a cylindrical soil specimen placed in rubber membrane with a diameter of $76 \mathrm{~mm}$ 
and varying heights. The soil specimen confined in the triaxial chamber can be subjected to both monotonic as well as cyclic uniform and irregular shear stresses. Cyclic tests can be performed on saturated soil specimens and pore water pressure can be measured during the undrained test. More details about $\mathrm{T}_{\mathrm{x}} \mathrm{SS}$ can be found in Chekired et al. (2015).

\section{Testing Program}

Three types of sands were collected from different areas in the province of Quebec with different physical properties; Baie-Saint-Paul (BSP) (relative density, $D_{r}=55 \%$ ), Carignon sand $\left(D_{r}=47\right.$ and 80\%) and Quebec sand $\left(D_{r}=64 \%\right)$. Physical properties of the used sands are summarized in Table 1. The grain-size distribution curves of these sands are shown in Fig. 1. Figure 1 shows also the range of grain-size distribution curves for liquefaction susceptible soils as proposed by Xenaki and Athanasopoulos (2003). As shown in Fig. 1, the used sands fall in the grain-size distribution ranges of liquefiable soils. A total of 24 tests have been conducted on isotropically consolidated soil samples using the $\mathrm{T}_{\mathrm{x}} \mathrm{SS}$ apparatus. Table 2 summarizes the conditions of all tests performed in this study.

Preparation method has significant effect on the pore pressure build-up and deformation pattern during cyclic loading (Sze and Yang 2014). The wet tamping preparation method was adopted to prepare reconstituted soil specimens in a rubber membrane in the $\mathrm{T}_{\mathrm{x}} \mathrm{SS}$ cell. This method was selected in the current study as it enables preparing reconstituted soil samples at wide range of initial density with high degree of precision (Sze and Yang 2014). In addition, it provides more isotropic fabric samples (Yang et al. 2008). Moist soil specimens of 76-mm diameters and 25-mm 
heights were prepared from the aforementioned sands in three layers. Park (1999) and Frost and Park (2003) concluded that the compaction stress must not be higher than the used confining pressure to avoid pre-stressing soil sample. Thus, each layer was compacted gently using hand tamper of $340 \mathrm{~g}$ until achieving the desired density. To saturate the soil specimen, carbon dioxide $\left(\mathrm{CO}_{2}\right)$ gas was flushed through each soil sample for 15 minutes. Subsequently, de-aired water was percolated through soil sample under a slight back pressure of $50 \mathrm{kPa}$ with cell pressure of $40 \mathrm{kPa}$ for 2 hours. Next, a back pressure of $200 \mathrm{kPa}$ was applied with cell pressure of $190 \mathrm{kPa}$ for 15 hours. To ensure the full saturation of the soil, the Skempton's pore pressure parameter $B\left(\Delta u / \Delta \sigma_{3}\right)$ was estimated for each test by measuring the increase in pore water pressure $\Delta u$, induced by increasing cell pressure by $\Delta \sigma_{3}$. Fully saturation was defined when $B$ greater than 0.96 was achieved. Once an acceptable $B$ value had been obtained, the soil specimen was isotropically consolidated under effective confining pressure of 75, 60, and $78 \mathrm{kPa}$ for $\mathrm{BSP}$, Carignon, and Quebec sands, respectively. After consolidation stage, all soil specimens under undrained condition were subjected to cyclic uniform or irregular shear strain time histories (strain-controlled) until initial liquefaction was occurred. Initial liquefaction is defined throughout this study as $R_{u}=0.9$. The uniform shear strains were applied on BSP and Carignon sands at a loading frequency of $1.0 \mathrm{~Hz}$, while Quebec sand was tested at $1.8 \mathrm{~Hz}$. It is noteworthy that frequency doesn't have significant effect on liquefaction potential (Boulanger et al. 1991; Polito 1999; Hazirbaba and Rathje 2009).

\section{Experimental results}

Typical records of $\mathrm{T}_{\mathrm{x}} \mathrm{SS}$ test $(\mathrm{Q} 4)$ on Quebec sand under uniform shear strain are presented in Fig. 2. Figure 2a portrays the variation of the cyclic stress ratio, CSR with 
the applied shear strain $\gamma_{c y c}$. Figure $2 \mathrm{~b}$ shows the build-up of the pore water pressure ratio $R_{u}$, with the time, while Fig. $2 \mathrm{c}$ presents the variation of the vertical deformation $\varepsilon_{v}$, with the time. Figure 2a shows that the hysteresis $\left(C S R-\gamma_{c y c}\right)$ loops become flatter with the increase of the number of cycles and ultimately turn out to be horizontal at initial liquefaction. The generation of the pore water pressure is accompanied by a gradual decrease in the $C S R$ as shown in Fig. 2b. The increase in the $R_{u}$ is associated with an increase in the vertical deformation $\varepsilon_{v}$, of soils as shown in Fig. 2c. The decrease of the $C S R$ value results from the degradation of the shear modulus of the soil that can be related to the pore water pressure ratio $R_{u}$, Eq. 9, (Matasovic and Vucetic 1993; Chang et al. 2007; Moreno-Torres et al. 2010):

$$
G=G_{\max }\left[1-R_{u}\right]^{0.5}
$$

in which $G_{\max }=$ the maximum shear modulus and $G$ is the shear modulus at any cycle.

Figure 3 presents liquefaction potential curves $\left(\gamma_{c y c}-N_{l i q}\right)$ of BSP, Carignon sand and Quebec sand, where $\gamma_{c y c}$ is the uniform shear strain and $N_{l i q}$ is the number of cycles required to cause liquefaction $\left(R_{u}=0.9\right)$. Table 2 summarizes the $N_{l i q}$ values obtained from all the tests conducted in the current study. All resistance $\left(\gamma_{c y c}-N_{l i q}\right)$ curves have the same trend, like CSR- $N_{l i q}$ curve, wherein $N_{l i q}$ is inversely proportional to the shear strain amplitude. Figure 3 shows the effect of the relative density of soils on the liquefaction potential wherein denser Carignon sand $\left(D_{r}=\right.$ $80 \%)$ has higher liquefaction resistances than the looser one $\left(D_{r}=47 \%\right)$ at different strain levels. This is in agreement with earlier observations by several researchers (e.g., Peacock and Seed 1968; Tatsuoka et al. 1987; Liu and Xu 2015). Although BSP $\left(D_{r}=55 \%, \sigma_{c o}^{\prime}=75 \mathrm{kPa}\right)$ and Carignon $\left(D_{r}=47 \%, \sigma_{c o}^{\prime}=60 \mathrm{kPa}\right)$ sands have close $D_{50}, C_{u}$, and $C_{c}$ values (Table 1) and are prepared at similar relative density, 
$D_{r(\text { consolidated })} \cong 60 \%$, their liquefaction potential curves are very different. This difference would be attributed to: (1) the difference in the particle shape characteristics (e.g., Kramer 1996; Cabalar et al. 2013) wherein the liquefaction potential of sand has angular particles shape (BSP sand) is higher than sand has rounded particles shape (Quebec sand); (2) state of stress wherein liquefaction potential increases with increasing the effective confining pressure (e.g., Youd et al. 2001; Liu and Xu 2015).

Based on the uniform strain-controlled test results and following the R-N cumulative damage hypothesis (Eq. 5), an empirical expression (Eq. 10) was developed to calibrate the material parameter $r$, using the pore water pressure build-up as damage metric:

$$
R_{\mathrm{u}}=0.9\left[R_{n}\right]^{r}
$$

Figure 4 presents a comparison between the measured pore water pressure ratio $R_{\text {u.exp., }}$ and that estimated from Eq. $10, R_{u . e s t .,}$ using the calibrated material parameter $r$. It can be observed that there is a good correspondence between measured and estimated pore water pressure ratio $R_{u}$. Therefore, the use of Eq. 10 in conjunction with measured pore water pressure can be considered as an alternative approach to calibrate $r$. Meanwhile, Green and Lee (2006) adopted the volumetric change procedure to calibrate the parameter $r$ based on Martin et al. (1975) model and its development by Byrne (1991).

The calibrated values of material parameter $r$, from Eq. 10 for BSP sand $\left(D_{r}=\right.$ 55\%), Carignon sand $\left(D_{r}=47\right.$ and $\left.80 \%\right)$ and Quebec sand $\left(D_{r}=64 \%\right)$ are listed in Table 2. The variation of $r$ with the applied shear strain amplitude $\gamma_{c y c}$, for tested sands is presented in Fig. 5. It is observed in all calibrated curves that the values of $r$, reduce with increasing the cyclic shear strain $\gamma_{c y c}$. Moreover, the $r$ changes from soil 
to another wherein Quebec sand has the lowest calibration curve while Carignon sand $\left(D_{r}=80 \%\right)$ has the highest one. This variation may be due to the change of particle shape while coefficient of uniformity $C_{u}$, and coefficient of curvature $C_{c}$, may not have a significant effect.

Liquefaction potential curves, Fig. 3, was used in conjunction with $r$, Fig. 5, to compute the cumulative damage by both P-M and R-N hypotheses, Eq. 5, of two synthetic non-uniform strain time histories (B6 and B7) applied on BSP sand. The first strain time history (B6), Fig. 6a, consists of four sequences of uniform strain cycles with amplitudes of $0.3,0.35,0.4$ and 0.45 , respectively. The second strain time history (B7), Fig. 6b, consists of five sequences of uniform strain cycles (three sequences with amplitude 0.45 interposed with two sequences having amplitude of 0.3). The P-M hypothesis can be yielded from Eq. 5 by setting $r=1$ for all strain amplitudes (Green and Lee 2006). The computed cumulative damages by both P-M and R-N hypotheses are compared to the measured $R_{u}$ after applying $\mathrm{B} 6$ and $\mathrm{B} 7$ in Figs. $6 \mathrm{a}$ and $6 \mathrm{~b}$, respectively. It is observed that the generated $R_{u}$ and the computed cumulative damage by R-N hypothesis are identical in both cases of B6 and B7. However, the corresponding cumulative damage by P-M hypothesis is significantly less than that obtained by R-N hypothesis and doesn't correctly reflect the generation of pore water pressure during cyclic loading.

In order to investigate the validity of using pore water pressure as damage metric under earthquake time history, two synthetic earthquake ground motions introduced by Atkinson (2009) in addition to an incompatible earthquake (from USA) were used in the current study. The synthetic earthquake ground motions were first matched to the spectral accelerations reference of class (A) (NBCC 2005) for BSP and Carignon regions (Fig. 7). The compatible accelerograms are shown in Figs 8a, 
and 8c wherein the incompatible earthquake shown in Fig. 8b. The computer code, FLAC 2D (Itasca 2010) was then utilized to analyze the response of the BSP and Carignon $\left(D_{r}=47 \%\right)$ sand deposits to the compatible and the incompatible accelerograms applied at their bases. The strain time histories response, synthetic 1 and synthetic 2, of BSP deposit to acc. 101 (Fig. 8a) and the incompatible earthquake (Fig. 8b) at certain depths (depending on the confining pressure applied in the test) are shown in Figs. 9a and 9b, respectively. Meanwhile, the strain time histories response, synthetic 3, of Carignon $\left(D_{r}=47 \%\right)$ deposit to acc. 103 (Fig. 8c) are shown in Fig. 9c. The strain time histories response were then applied to the BSP, B8 and B9, and Carignon $\left(D_{r}=47 \%\right), \mathrm{C} 1-6$, sand samples in the $\mathrm{T}_{\mathrm{x}} \mathrm{SS}$ apparatus. The recorded $R_{u}$ are compared to the cumulative damage computed using the P-M and the R-N hypotheses in Figs. 9a, 9b and 9c. It is noteworthy that the peak counting method was used to determine the number of peaks and valleys in earthquake time history. By applying this method, all peaks above reference level (x-axis) and valleys below reference level (x-axis) in earthquake time history are counted (Green and Terri 2005; Hancock and Bommer 2005; ASTM 2011). All counted peaks and valleys in computing the cumulative damage are marked as (x) in Fig. 9. Each peak or valley value represents a half loading cycle (Seed at al. 1975a; ASTM 2011). In contrast to the previous work by Seed et al. (1975a) wherein neglecting small amplitude cycles don't influence results, all amplitudes are counted in the current study in calculation of pore water pressure build-up "cumulative damage" and inherent in computing equivalent number. Figures $9 \mathrm{a}, 9 \mathrm{~b}$ and $9 \mathrm{c}$ show that the computed cumulative damage using the R-N hypothesis is in good agreement with the measured pore water pressure for both BSP and Carignon sands. However, the cumulative damage computed by P-M hypothesis doesn't correctly reflect the cumulative damage (i.e., the generated pore 
water pressure) during cyclic loading. That can be attributed to the deficiency of the P-M hypothesis to account for the sequence of loading peaks. As the R-N hypothesis considers the load sequence; it can be used in an acceptable degree of accuracy to compute cumulative damage, which represents pore water pressure build-up, during uniform, non-uniform, and irregular earthquake shear strain time histories (Figs. 4, 6, and 9) which was theoretically concluded earlier by Green and Lee (2006).

\section{Converting earthquake strain time history to equivalent uniform strain cycles,} $N_{e q \gamma}$

As shown in the previous section, there is a good agreement between the computed cumulative damage using R-N hypothesis and the measured pore water pressure. So, a new formula alternative to Eq. 7 can be used to predict $N_{\text {eqr }}$ up to liquefaction occurrence, i.e., $R_{u}=0.9$, using the measured pore water pressure in the $\mathrm{T}_{\mathrm{x}} \mathrm{SS}$ apparatus as damage metric:

$$
N_{e q \gamma}=N_{\text {Liq.ref }}\left[R_{u}\right]^{1 / r_{\text {ref }}}
$$

in which, $R_{u}$ is the measured pore water pressure ratio after applying cyclic strain time history; $N_{\text {liq.ref }}$ is the number of the uniform strain cycles having amplitude $\gamma_{\text {ref }}$ required to the liquefaction occurrence, Fig. 3, and $r_{r e f}$ is the calibrated material parameter corresponding to $\gamma_{\text {ref, }}$, Fig. 5.

Figures $10 \mathrm{a}, 10 \mathrm{~b}$ and $10 \mathrm{c}$ compare the generated pore water pressure ratio $R_{u}$ in BSP sand samples after applying uniform strain cycles $\gamma_{c y c}$, of $0.75,0.525$, and 0.33 with that generated after applying B6 (Fig. 6a), B8 (Fig. 9a) and B9 (Fig. 9b), respectively. While, Fig. 10d compares the generated $R_{u}$ in Carignon sand $\left(D_{r}=47 \%\right)$ after applying uniform strain cycles $\gamma_{c y c}$, of 0.27 and 0.20 with that generated after 
applying C1-6 (Fig. 9c). Numbers of uniform strain cycles $N_{\text {eqr }}$, required to generate $R_{u}$ of $0.6,0.42$ and 0.9 (corresponding to test $\mathrm{B} 6, \mathrm{~B} 8$ and $\mathrm{B} 9$ ) in BSP sand samples are listed in Tables 3a, 3b and 3c, respectively. Meanwhile, numbers of uniform strain cycles $N_{e q r}$ required to generate $R_{u}$ of 0.205 (corresponding to C1-6) in Carignon sand samples are listed in Tables $3 \mathrm{~d}$. The corresponding values of $N_{\text {eqr }}$ computed using the P-M and R-N hypotheses (Eqs. 3 and 7) in conjunction with liquefaction potential curves $\left(\gamma_{c y c}-N_{l i q}\right)$ in Fig. 3, of BSP sand (B6, B8 and B9), and Carignon sand (C1-6) are also listed in Table 3. In fact, the liquefaction potential curves $\left(\gamma_{c y c}-N_{l i q}\right)$ are used as weighting curves wherein $N_{l i q}$ for each peak in earthquake strain time history can be determined. It can be seen from the values presented in Table 3 for both BSP and Carignon sands that there is a good agreement between the computed $N_{\text {eqr }}$ using R-N hypothesis, Eq.7, and the experimentally determined values (Fig. 10) adopting pore water pressure as damage metric which strongly confirms the use of Eq. 11 in computation of $N_{e q \gamma}$ On the other hand, the values of $N_{\text {eqr }}$ computed using P-M hypothesis, Eq.3, especially for Carignon sand is overestimated in consistence with the results reported earlier by Green and Lee (2006) based on their theoretical approach. However, in the case of liquefaction occurrence (test B9), both cumulative damage hypotheses (R-N and P-M) yielded $N_{\text {eqr }}$ values equal to that obtained by using pore water pressure build-up as damage metric. These results provide experimental credence for the use of R-N hypothesis in computing the cumulative damage and the equivalent number of strain cycles $N_{e q \gamma}$.

\section{Conclusions}

Following the theoretical work by Green and Lee (2006), a series of experimental work was conducted using a new combined triaxial simple shear $\left(\mathrm{T}_{\mathrm{x}} \mathrm{SS}\right)$ apparatus to 
investigate the equivalent number concept. Uniform strain-controlled tests were conducted under undrained condition on reconstituted sample of BSP, Carignon, and Quebec sands to develop $\left(\gamma_{c y c}-N_{l i q .}\right)$ curves analogous to the typical $\left(C S R-N_{l i q .}\right)$ curves that can be used in liquefaction assessment and $N_{e q \gamma}$ estimation. Pore water pressure generated in uniform strain-controlled tests was used as damage metric with an adequate degree of accuracy to calibrate the material parameter $r$. It is observed that material parameter is a function of soil type, cyclic shear strain amplitude $\gamma_{c y c}$, and soil density.

Using the calibrated material parameter to apply R-N hypothesis on nonuniform and earthquake time histories results in good agreement between the measured pore water pressure and the computed cumulative damage. However, the current study shows that the P-M hypothesis underestimates the cumulative damage (i.e., the generated pore water pressure) during cyclic loading till the onset of liquefaction. Furthermore, a comparison between the computed $N_{\text {eq }}$ using $R-N$ for irregular strain time history applied on BSP and Carignon sands shows a good agreement with those experimentally estimated considering pore water pressure buildup as damage metric. At the onset of liquefaction, using $P-M$ hypothesis yields $N_{\text {eqr }}$ values equal to that obtained by R-N hypothesis and by pore water pressure build-up as damage metric. However, prior the trigger of liquefaction, P-M hypothesis leads to overly conservative prediction of $N_{\text {eq }}$ confirming previous findings by Green and Lee (2006). These results indicate the possibility of using pore water pressure as damage metric till occurrence of liquefaction to estimate $N_{e q \gamma}$. 


\section{References}

Annaki. M. and Lee. K.L. 1977. "Equivalent uniform cycle concept for soil dynamics." J. Geotech. Eng. Div., 103(6), 549-564.

ASTM. 2011. "Practices for cycle counting in fatigue analysis." ASTM E1049, 1985, West Conshohocken, PA.

Atkinson, G. M. 2009. "Earthquake time histories compatible with the 2005 National building code of Canada uniform hazard spectrum." Can. Geotech. J., 36(6), 9911000 .

Boulanger, R. W., Seed, R. B., Chan, C. K., Seed, H. B., and Sousa, J. 1991. "Liquefaction behavior of saturated sands under unidirectional and bi-directional monotonic and cyclic simple shear loading." Rep. No. UCB/GT/91-08, Univ. of California, Berkeley, Calif.

Byrne. P.M. 1991. "A Cyclic Sher Volume Coupling and Pore-Pressure Model for Sand." Proc. 2nd Int. Conference on Recent Advances in Geotechnical Engineering and Soil Dynamics, St Louis, (1.24), 47-55.

Cabalar, A.F., Dulundu, K. and Tuncay, K. 2013. "Strength of various sands in triaxial and cyclic direct shear tests.” Engineering Geology, 156, 92-102.

Carter, L., Green, R., Bradley, B., and Cubrinovski, M. 2013. "The influence of nearfault motions on liquefaction triggering during the Canterbury earthquake sequence." Proc. of New Zealand - Japan Workshop on Soil Liquefaction during Recent Large-scale Earthquakes, 51-61.

Chang, W.J., Rathje, E.M., Stokoe, K.H., and Hazirbaba, K. 2007. "In situ porepressure generation behavior of liquefiable sand." J. Geotech. Geoenviron. Eng., 133(8), 921-931.

Chekired, M., Lemire, R., Karray, M., and Hussien, M.N. 2015. "Experiment setup for simple shear tests in a triaxial cell : $\mathrm{T}_{\mathrm{x}} \mathrm{SS}$." Proc. 68th Conf. Canadian of Geotech., Quebec, paper no. 365.

DeAlba. P., Chan. C.K., and Seed. H.B. 1975. "Determination of soil liquefaction characteristics by large-scale laboratory tests." Rep. No. EERC 75-14: Earthquake Engineering Research Center. Univ. of California, Berekely, Calif.

Dobry, R., Ladd, R.S., Yokel, F.Y., Chung, R.M., and Powell, D. 1982. "Prediction of Pore Water Pressure Buildup and Liquefaction of Sand During Earthquakes by the Cyclic Strain Method.” National Bureau of Standards Building Science Series 
138, Washington, DC.

Dobry, R., Pierce, W.G., Dyvik, R., Thomas, G.E., and Ladd, R.S. 1985. "Pore pressure model for cyclic straining of sand.” Rensselaer Polytechnic Institute, Troy, New York.

Dobry, R., and Vucetic, M. 1987. "Dynamic properties and seismic response of soft clay deposits." Int. symposium on geotechnical engineering of soft soils, Mexico City, 51-87.

Frost, J.D., and Park, J.-Y. 2003. "A critical assessment of the moist tamping technique." Geotechnical Testing Journal, 26(1): 1-14.

Green, R.A., and Lee. J. 2006. "Computation of number of equivalent strain cycles: a theoretical framework." Geomechanics II: Testing, modeling, and simulation, $156,471-487$.

Green, R.A. 2001. "Energy-based evaluation and remediation of liquefiable soils." $\mathrm{PhD}$ dissertation, Virginia Polytechnic Institute and State Univ., Blacksburgh, Va., <http://scholar.lib.vt.edu/theses/available/etd-08132001-170900/>.

Green, R.A., and Terri, G.A. 2005. "Number of Equivalent Cycles Concept for Liquefaction Evaluations-Revisited.” J. Geotech. Geoenviron. Eng., 131(4), $477-488$.

Haldar, A., and Hochaimi. N.S. 1984. "Uniform Cycles in Earthquake Motions." In 8th World Conf. on Earthquake Engineering, San Francisco, California, 151157.

Hancock, J., and Bommer, J.J. 2005. "The effective number of cycles of earthquake ground motion.” Earthquake Eng. Struct. Dyn., 34(6), 637-664.

Hazirbaba, K., and Rathje, E.M. 2009. "Pore pressure generation of silty sands due to induced cyclic shear strains.” J. Geotech. Geoenviron. Eng., 135(12), 1892-1905.

Ishihara, K., and Nagase, H. 1988. "Multi-directional irregular loading tests on sand." Soil Dyn. Earthquake Eng., 7(4), 201-212.

Itasca Consulting Group Inc. 2010. Fast lagrangian analysis of continua in 2dimensions 6.0, manual. Itasca, Minneapolis.

Juang, C.H., Yuan, H., Lee, D.H., and Lin, P.S. 2003. "Simplified cone penetration test-based method for evaluating liquefaction resistance of soils." J. Geotech. Geoenviron. Eng., 129(1), 66-80.

Kazama, M., Yamaguchi, A., and Yanagisawa, E. 2000. "Liquefaction 
resistance from a ductility viewpoint." Soils Found., 40(6), 47-60.

Kramer, S.L. 1996. “Geotechnical Earthquake Engineering.” Publ. Prentice Hall, 348422

Lasley, S.J., Green, R.A., and Rodriguez-Marek, A. 2016. "Number of equivalent stress cycles for liquefaction evaluations in active tectonic and stable continental regimes.” J. Geotech. Geoenviron. Eng., 143(4), 04016116-1- 04016116-11.

Lee, K.L., and Chan, K. 1972. "Number of equivalent significant cycles in strong motion earthquakes." In Proc. Int. Conf. on Microzonation for Safer Construction Research and Application, University of Washington, 2, 609-627.

Lenart, S. 2008. "The use of dissipated energy at modeling of cyclic loaded saturated soils." Earthquake Engineering: New Research. Nova Science Publishers. Chapter 8 .

Liu, A.H., Stewart, J.P., Abrahamson, N.A., and Moriwaki, Y. 2001. "Equivalent number of uniform stress cycles for soil liquefaction analysis." J. Geotech. Geoenviron. Eng., 127(12), 1017-1026.

Liu, C., and Xu, J. 2015. "Experimental study on the effects of initial conditions on liquefaction of saturated and unsaturated sand." Int. J. Geomech., 15(6), 4014100-1-04014100-10.

Martin, G.R., Finn. W.D.L., and Seed. H.B. 1975. "Fundementals of liquefaction under cyclic loading." J. Geotech. Geoenviron. Eng., 101(5), 423-438.

Matasovic, N., and Vucetic, M. 1993. "Cyclic characterization of liquefiable sands." J. Geotech. Geoenviron. Eng., 119(11), 1805-1822.

Miner, M.A. 1945. "Cumulative damage in fatigue." Trans. ASME 67, 159-164.

Moreno-Torres, O., Hashash, Y.M.A., and Olson, S.M. 2010. “A simplified coupled soil-pore water pressure generation for use in site response analysis." Advances in Analysis, Modeling and Design, 3080-3089.

National Research Council 1985. "Liquefaction of Soils during Earthquakes." National Academy Press, Washington, DC, 240.

Nemat-Nasser, S., and Shokooh, A. 1979. "A unified approach to densification and liquefaction of cohesionless sand in cyclic shearing." Can. Geotech. J. 16(4), $659-678$

Palmgren, A. 1924. "Die lebensdauer von kugella geru." ZVDI, 68(14), 339-341.

Park, J. Y. 1999. "A Critical assessment of moist tamping and its effect on the initial 
and evolving structure of dilatant triaxial specimens," partial fulfillment of the requirements for the degree of Doctor of Philosophy, Georgia Institute of Technology.

Peacock, W.H., and Seed, H. 1968. "Sand liquefaction under cyclic loading simple shear conditions.” J. Soil Mech. Found. Div., 94(3), 689-708.

Polito, C.P. 1999. "The effects of non-plastic and plastic fines on the liquefaction of sandy soils.” Ph.D. dissertation, Virginia Polytechnic Institute and State Univ., Blacksburg, Va., 274.

Polito, C.P., Green. R.A., and Lee, J. 2008. "Pore Pressure Generation Models for Sands and Silty Soils Subjected to Cyclic Loading." J. Geotech. Geoenviron. Eng., 134(10), 1490-1500.

Rahman, M.M., Baki, M.A.L., and Lo, S.R. 2014. "Prediction of undrained monotonic and cyclic liquefaction behavior of sand with fines based on the equivalent granular state parameter." Int. J. Geomechanics, 14(2), 254-266.

Richart, F.E., and Newmark. N. 1948. "An Hypothesis for Determination of Cumulative Damage in Fatigue.” ASTM Proceedings, 48, 767-800.

Seed. B., and Lee, K.L. 1966. "Liquefaction of saturated sands during cyclic loading." J. Geotech. Geoenviron. Eng., 92(6), 105-134.

Seed, H.B., and Idriss, I.M. 1971. "Simplified procedure for evaluating soil liquefaction potential.” J. Soil Mech. Found. Div., 97(9), 1249-1273.

Seed, H.B., Idriss, I. M., and Arango, I. 1983. "Evaluation of liquefaction potential using field performance data." J. Geotech. Eng., 109(3), 458-482.

Seed, H.B., Idriss. I.M., Makdisi. F., and Banerjee, N. 1975a. "Representation of irregular stress time histories by equivalent uniform stress series in liquefaction analysis.” Rep. No. EERC 75-29, Earthquake Engineering Research Center, College of Engineering, Univ. of California, Berkeley, Calif.

Seed, H.B.. Martin, P.P., and Lysmer, J. 1975b. "The generation and dissipation of pore water pressures during soil liquefaction.” Rep. No. EERC 75-26, Earthquake Engineering Research Center, College of Engineering, Univ. of California, Berkeley, Calif.

Silver, M.L., and Park, T.E.D.K. 1976. "Liquefaction potential evaluated from cyclic strain-controlled properties tests on sands." Soils and Found., 16(3), 51-65.

Silver, M.L., and Seed, H.B. 1971. "Deformation characteristics of sands under cyclic 
loading.” J. Soil Mech. Found. Div., 97(8),1081-1098.

Sitharam, T.G., Ravishankar, B.V., and Patil, S.M. 2012. "Liquefaction and pore water pressure generation in sand: cyclic strain controlled triaxial tests" Int. J. Geotech. Earthquake Eng. (IJGEE), 3(1), 57-85.

Talaganov, K.V. 1996. "Stress-strain transformations and liquefaction of sands." Soil Dyn. Earthquake Eng., 15(7), 411-418.

Sze, H.Y., and Yang, J. 2014. "Failure Modes of Sand in Undrained Cyclic Loading: Impact of Sample Preparation.” J. Geotech. Geoenviron. Eng., 140(1), 152-169.

Tatsuoka, F., Muramatsu, M., and Sasaki, T. 1982. "Cyclic undrained stress-strain behavior of dense sands by torsional simple shear test." Soils and Foundations, $22(2), 55-70$.

Tokimatsu, K., and Seed, H.B. 1987. "Evaluation of settlements in sands due to earthquake shaking." J. Geotech. Eng., 113(8), 861-878.

Vucetic, M. 1994. "Cyclic threshold shear strains in soils.” J. Geotech. Eng., 120(12), $2208-2228$.

Vucetic, M., and Dobry, R. 1988. "Cyclic triaxial strain controlled testing of liquefiable sands." Advanced Triaxial Testing of Soil and Rock, ASTM STP 977, ed. R. T. Donaghe, R. C. Chancy and M. L. Silver, American Society for Testing and Materials, Philadelphia, 475-85.

Wer, R., and Dobry, R. 1982. "The equivalent number of cycles of recorded accelerograms for soil liquefaction studies.” M.Sc. thesis, Rensselaer Polytechnic Institute. Troy. N.Y.

Xenaki, V.C., and Athanasopoulos, G.A. 2003. "Liquefaction resistance of sand-silt mixtures: An experimental investigation of the effect of fines." Soil Dyn. Earthquake Eng., 23(3), 183-194.

Yang, J., Yang, Z.X., and Li, X.S. 2008. "Quantifying and modelling fabric anisotropy of granular soils." Géotechnique, 58(4), 237-248.

Youd, B.T.L., Idriss, I.M., Andrus, R.D., Arango, I., Castro, G., Christian, J.T., Dobry, R., Finn, W.D.L., Harder Jr., L.F., et al. 2001. "Liquefaction Resistance of Soils : Summary Report From the 1996 Nceer and 1998 Nceer/Nsf Workshops on Evaluation.” J. Geotech. Geoenviron. Eng., 127(10), 817-833. 


\section{Figure Captions}

Fig. 1: Grain-size distribution curves of the used sands.

Fig. 2: Typical records of $\mathrm{T}_{\mathrm{x}} \mathrm{SS}$ test (Q4) on Quebec sand (a) Hysteresis loop (CSR$\gamma_{\text {cyc }}$ ), (b) CSR and $R_{u}$ vs time, (c) Shear strain and vertical deformation vs time.

Fig. 3: Variation of cyclic shear strain, $\gamma_{\text {cyc }}$ with $N_{\text {liq }}$.

Fig. 4: Validation of the proposed relation: (a) BSP sand, (b) Carignon sand, (c) Quebec sand, and (d) $R_{u}-R_{n}$ relations for all the aforementioned sands.

Fig. 5: Calibration of the material parameter, $r$.

Fig. 6: Relation between applied $\gamma_{\text {cyc }}$, measured $\mathrm{Ru}_{\text {exp }}$, cumulative damage computed by P-M and R-N hypotheses for BSP sand: (a) non-uniform (B6), and (b) non-uniform (B7).

Fig. 7: Acceleration spectra for the used accelerations.

Fig. 8: Acceleration time history used in current study for: (a), (b) BSP sand, and (c) Carignon sand.

Fig. 9: Relation between applied $\gamma_{\text {cyc }}$, measured $R_{u}$, cumulative damage by P-M and R-N hypotheses for: (a) BSP sand (B8), (b) BSP sand (B9), and (c) Carignon sand (C1-6).

Fig. 10: Excess pore water pressure ratio versus time required to cause: (a) $R_{u}=0.6$ for BSP, (b) $R_{u}=0.42$ for BSP, (c) $R_{u}=0.9$ for BSP, and (d) $R_{u}=0.205$ for Carignon sands. 


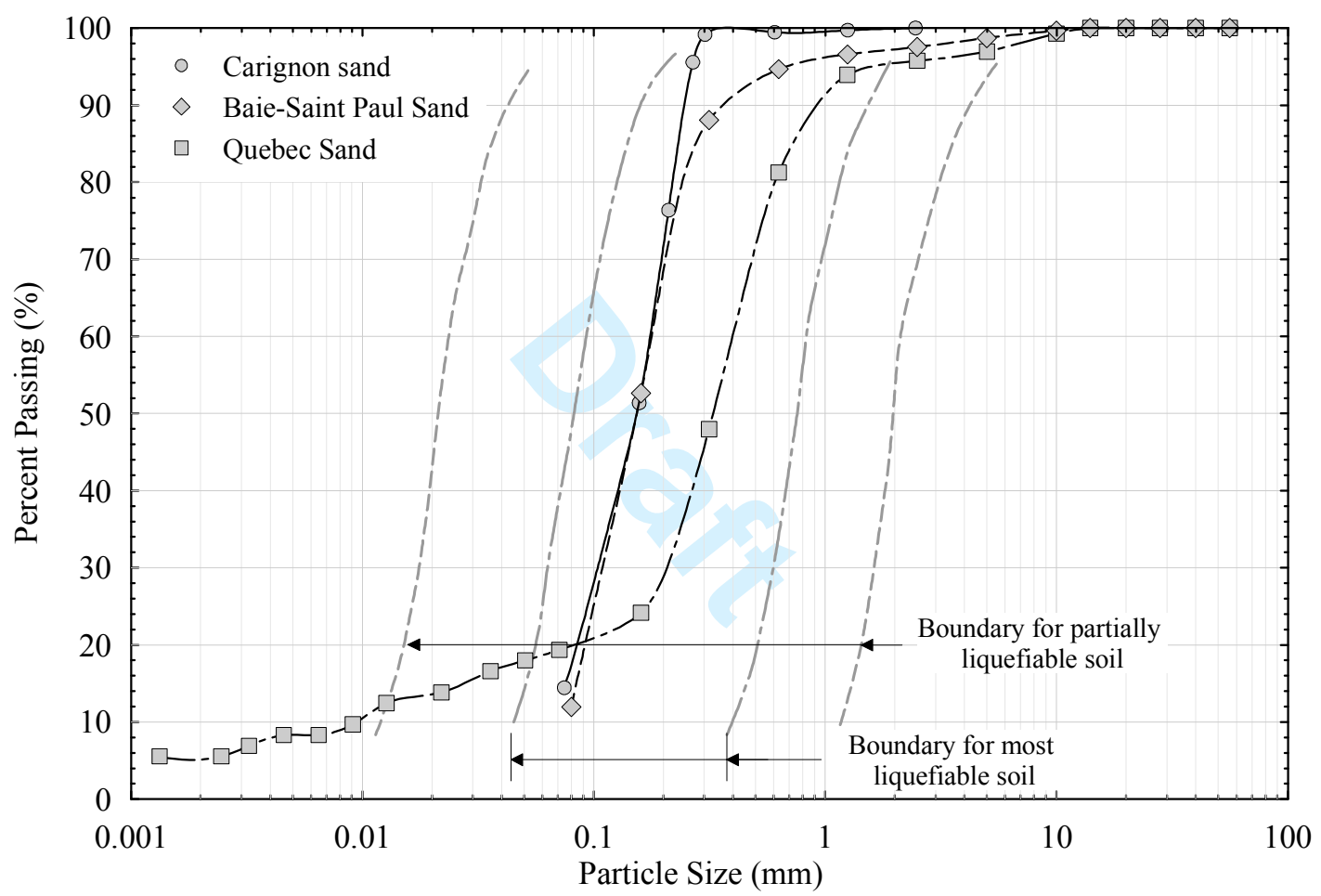

Fig. 1: Grain-size distribution curves of the used sands. 

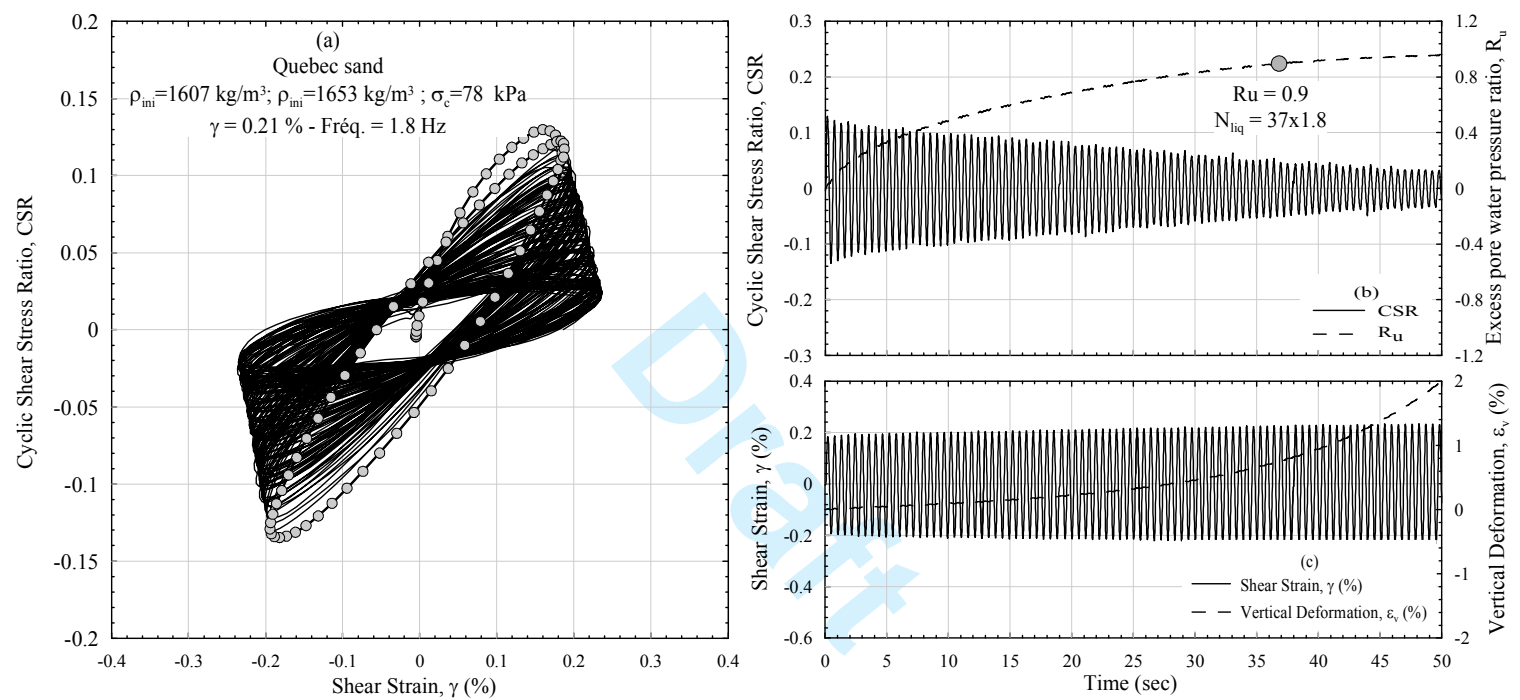

Fig. 2: Typical records of $T_{x} S S$ test (Q4) on Quebec sand (a) Hysteresis loop (CSR- $\left.\gamma_{c y c}\right)$, (b) CSR and $R_{u}$ vs time, (c) Shear strain and vertical deformation vs time. 


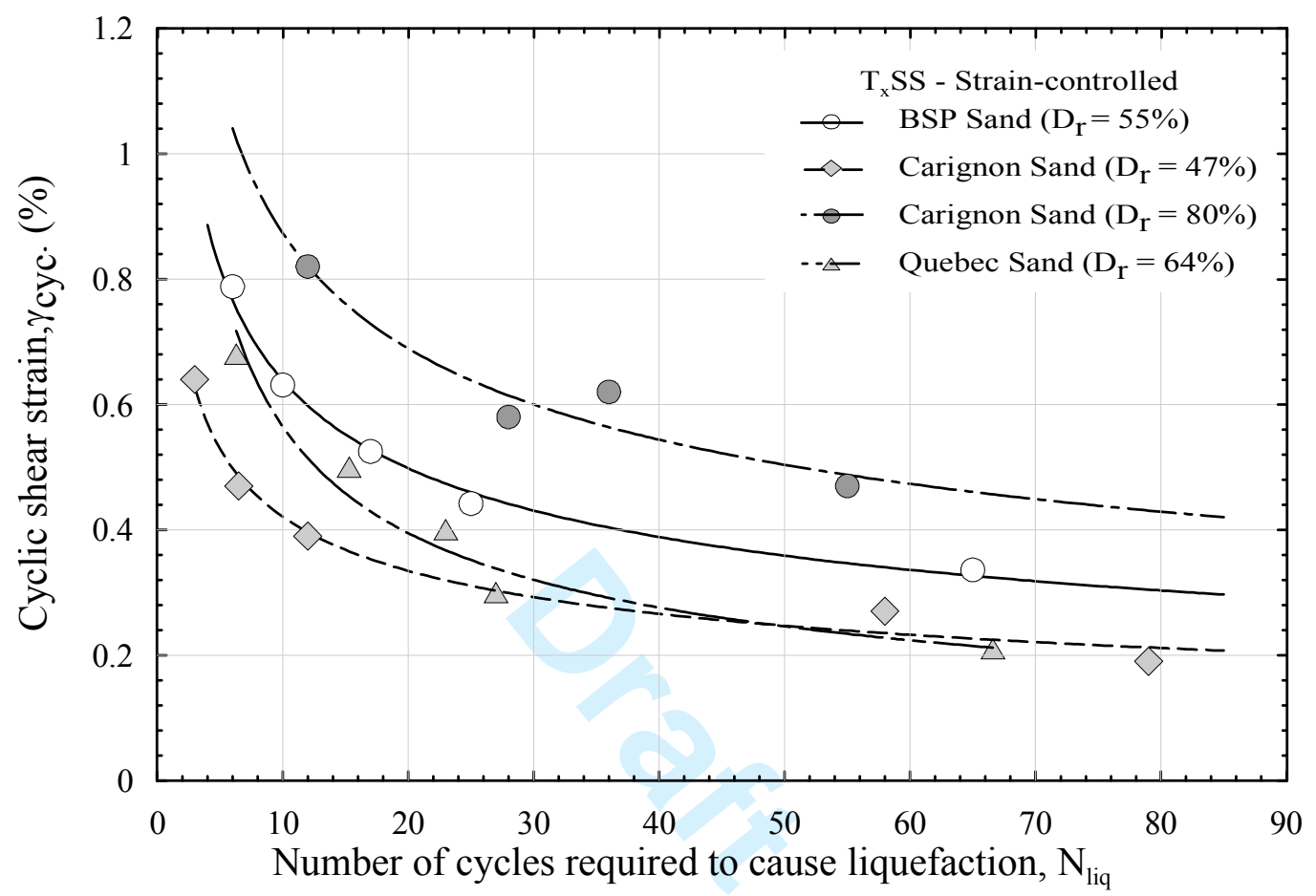

Fig. 3: Variation of cyclic shear strain, $\gamma_{\mathrm{cyc}}$ with $N_{\text {liq }}$. 

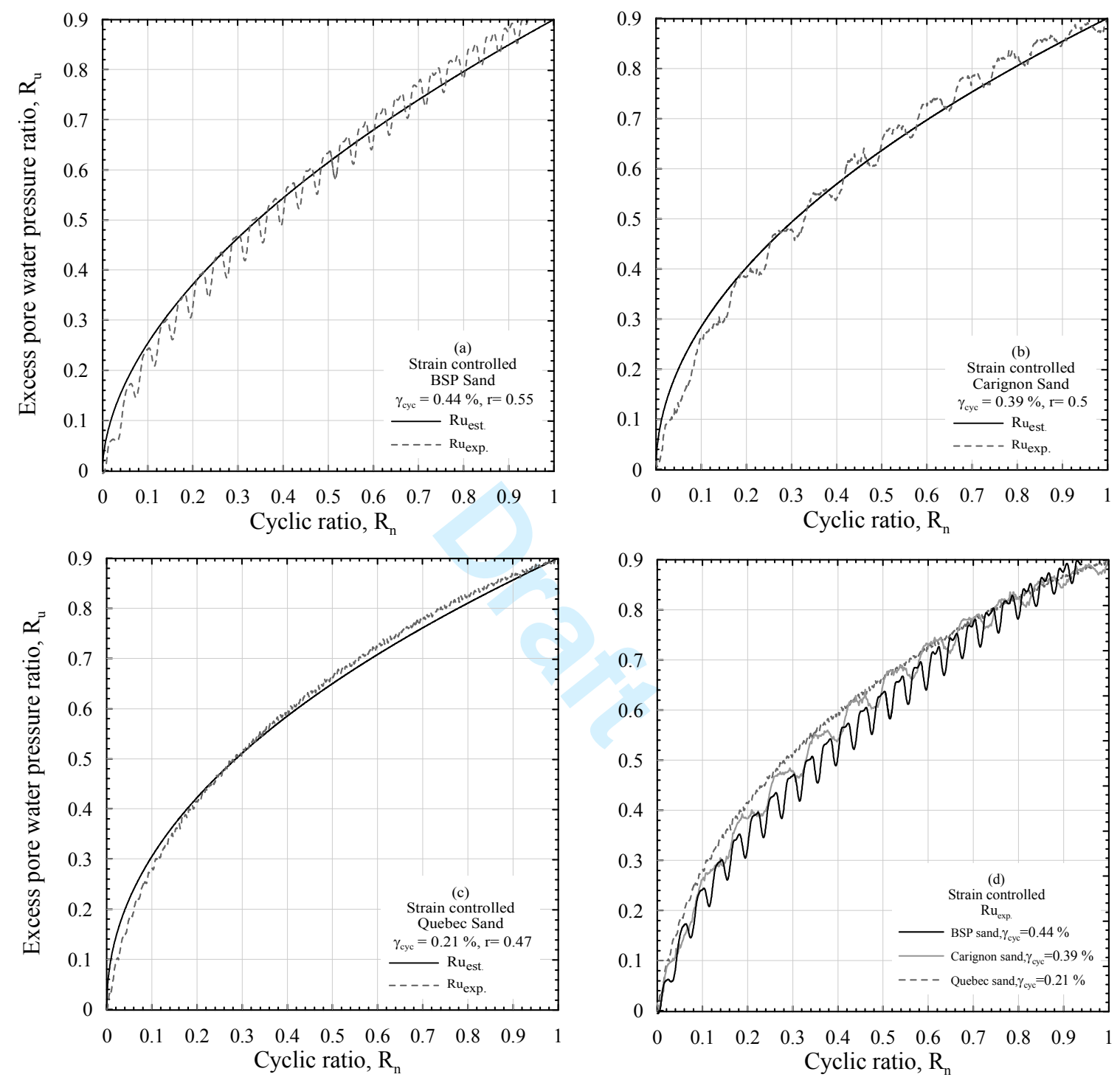

Fig. 4: Validation of the proposed relation: (a) BSP sand, (b) Carignon sand, (c) Quebec sand, and (d) $R_{u}-R_{n}$ relations for all the aforementioned sands. 


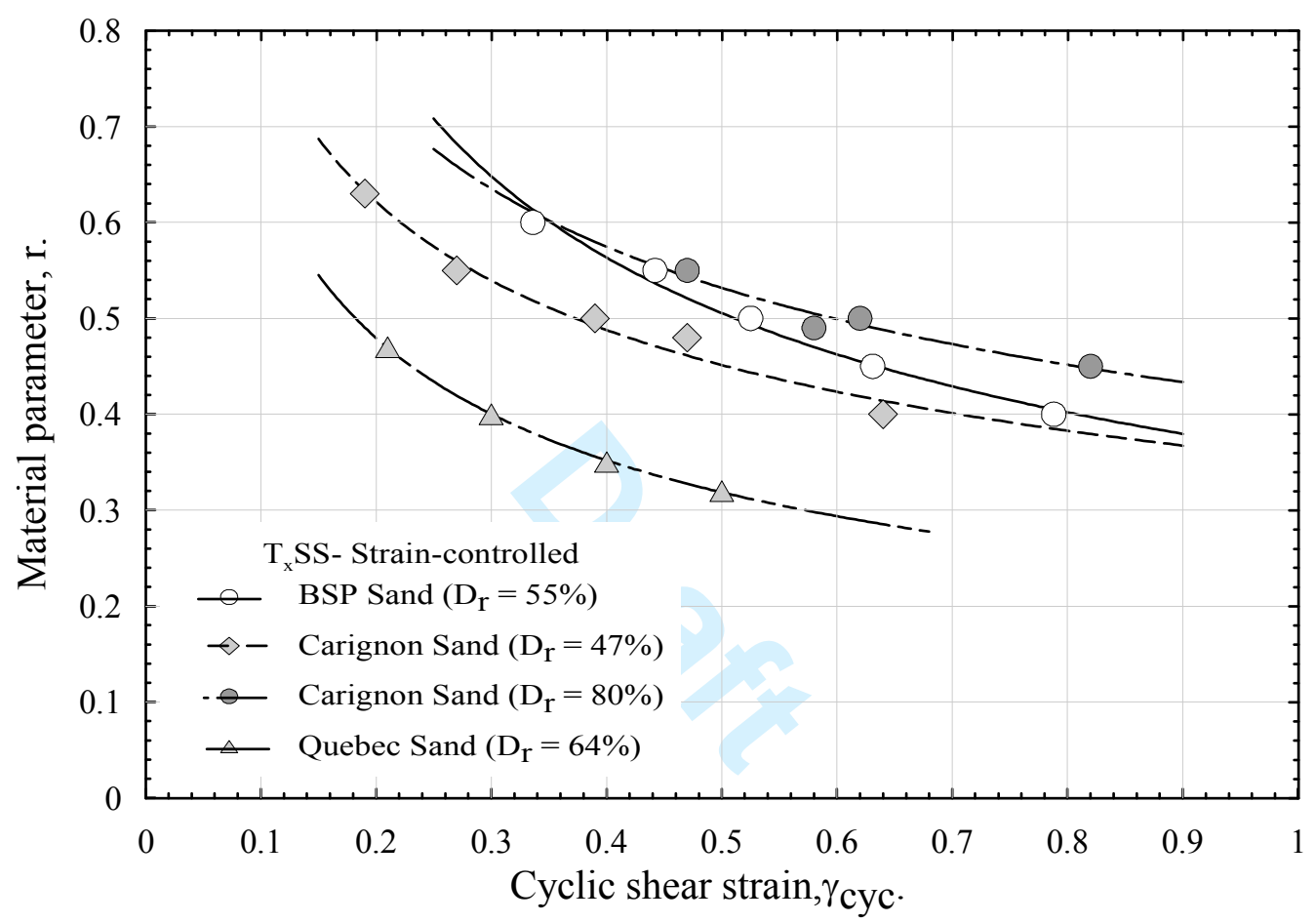

Fig. 5: Calibration of the material parameter, $r$. 

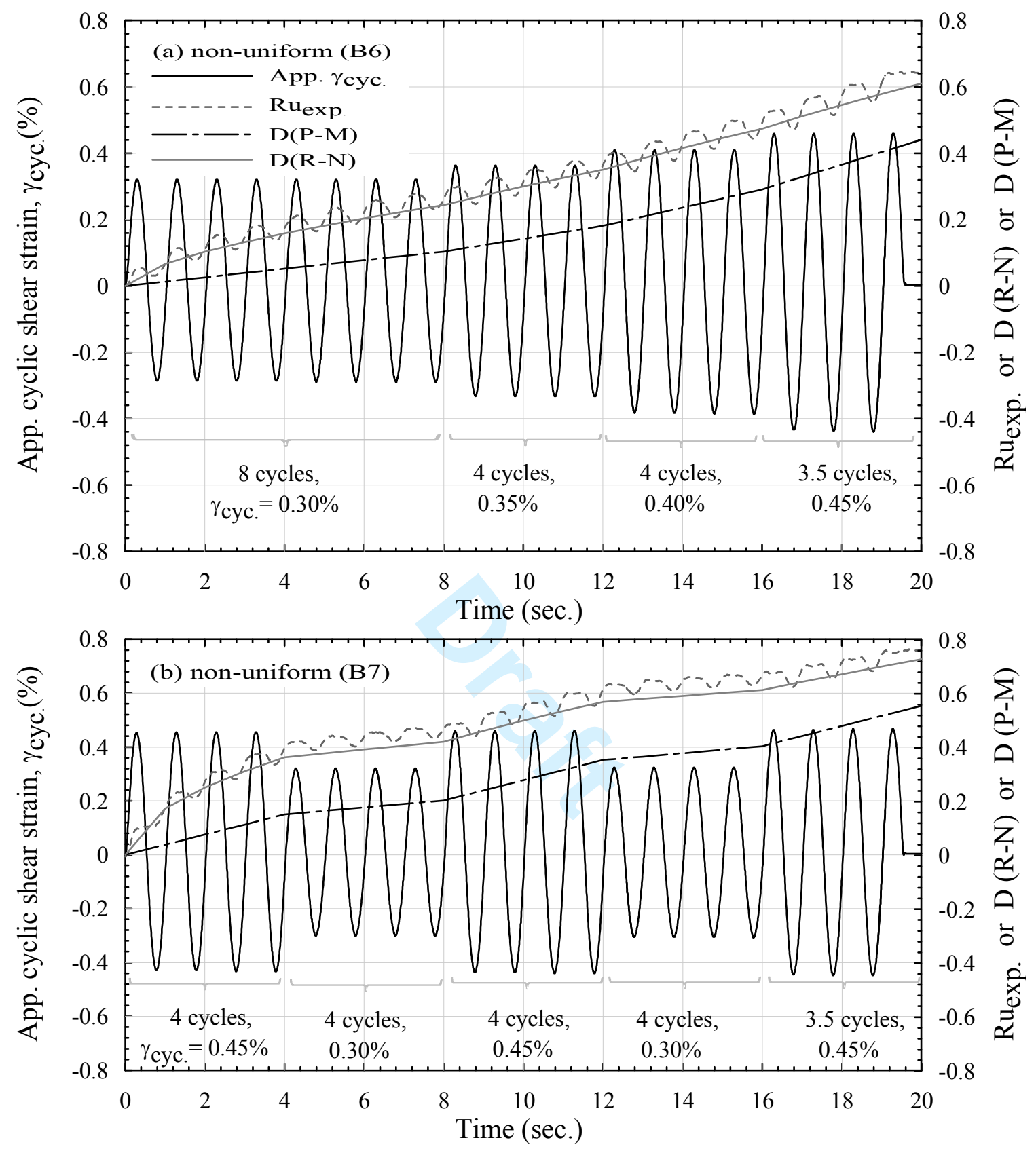

Fig. 6: Relation between applied $\gamma_{\text {cyc }}$, measured $\mathrm{Ru}_{\mathrm{exp}}$, cumulative damage computed by P-M and R-N hypotheses for BSP sand: (a) non-uniform (B6), and (b) non-uniform (B7). 


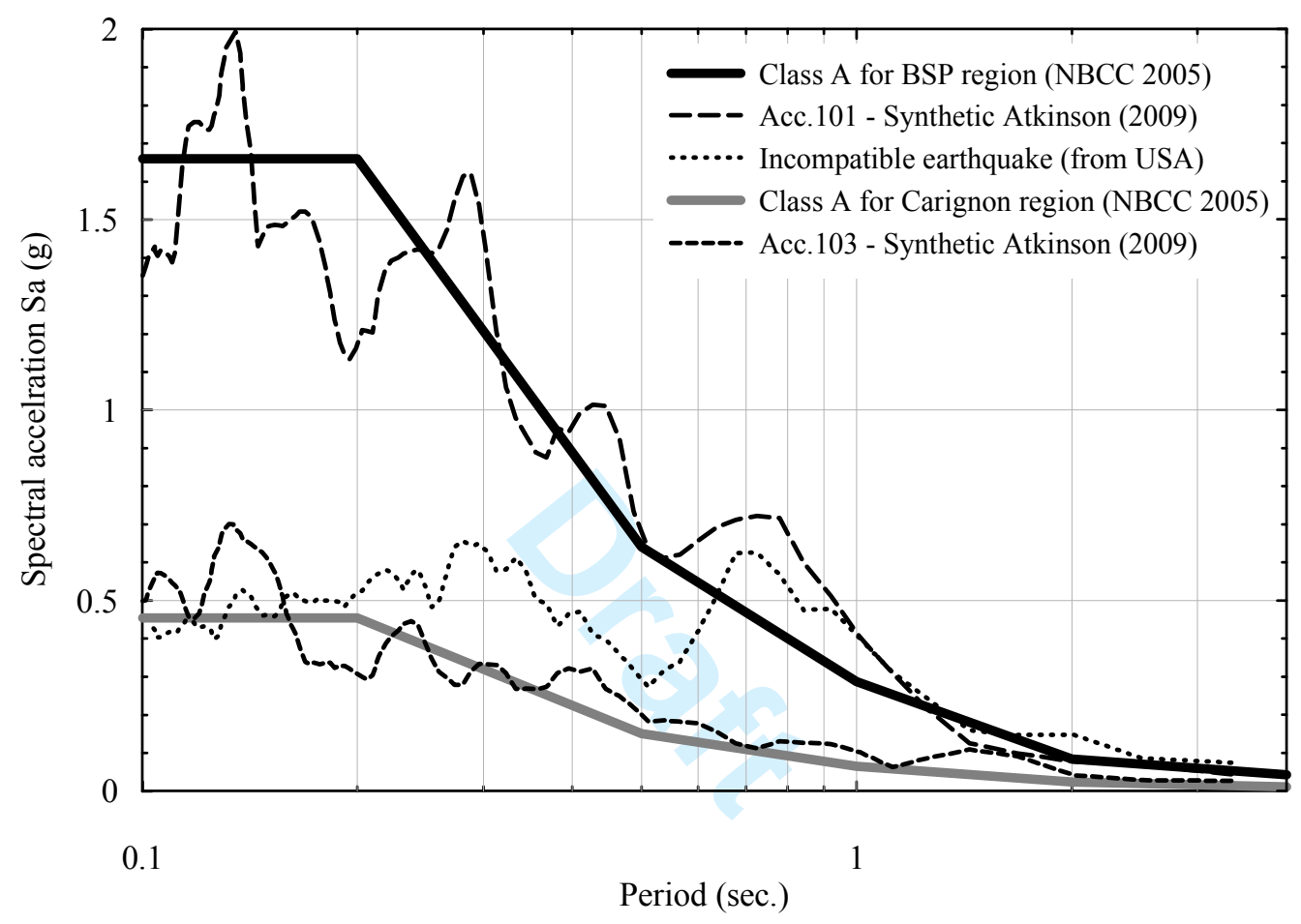

Fig. 7: Acceleration spectra for the used accelerations. 

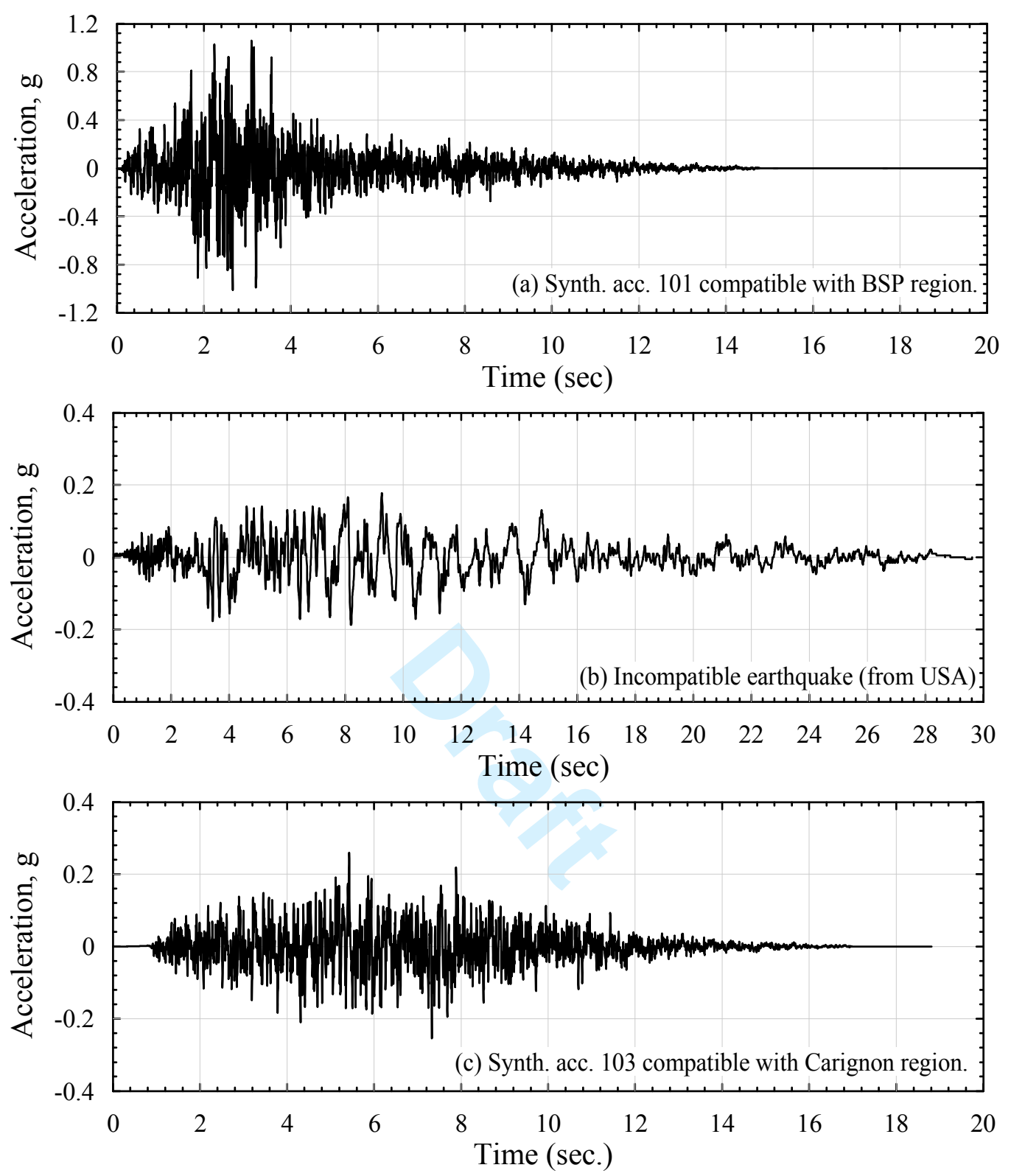

Fig. 8: Acceleration time history used in current study for: (a), (b) BSP sand, and (c) Carignon sand. 

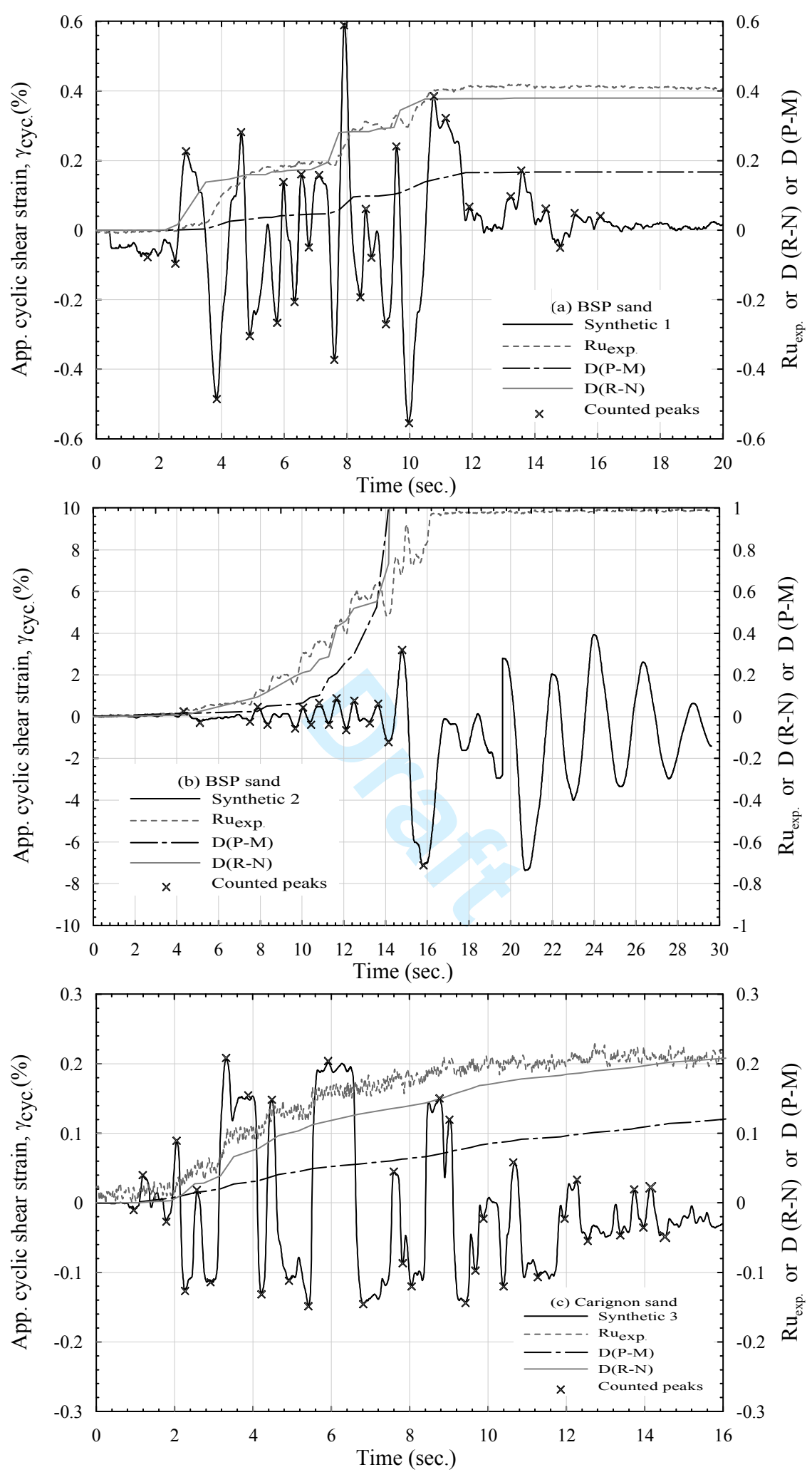

Fig. 9: Relation between applied $\gamma_{\text {cyc }}$, measured $R_{u}$, cumulative damage by P-M and R-N hypotheses for: (a) BSP sand (B8), (b) BSP sand (B9), and (c) Carignon sand (C1-6). 

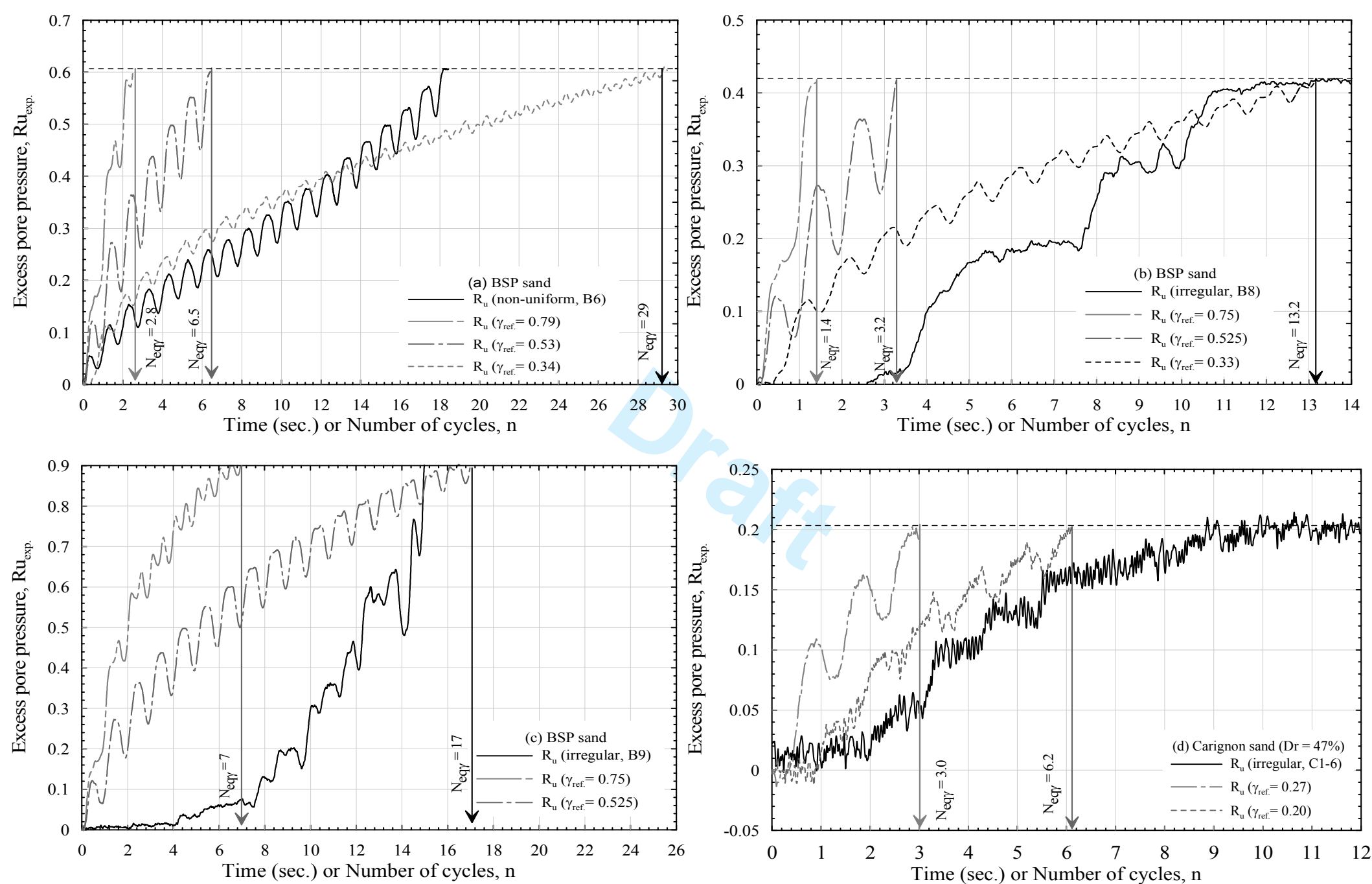

Fig. 10: Excess pore water pressure ratio versus time required to cause: (a) $R_{u}=0.6$ for $B S P$, (b) $R_{u}=0.42$ for $B S P$, (c) $R_{u}=0.9$ for BSP, and (d) $R_{u}=0.205$ for Carignon sands. 
Table 1: Physical properties of the used sands

\begin{tabular}{llll}
\hline Soil properties & Baie-Saint-Paul sand & Carignon sand & Quebec sand \\
\hline$G_{s}$ & 2.78 & 2.71 & 2.71 \\
$e_{\max }$ & 0.91 & 1.12 & 0.95 \\
$e_{\min }$ & 0.60 & 0.73 & 0.55 \\
$C_{u}$ & 2.25 & 2.45 & 44.44 \\
$C_{c}$ & 1.00 & 1.00 & 12.25 \\
$D_{50}$ & 0.15 & 0.15 & 0.33 \\
\hline
\end{tabular}


Table 2: Summary of test conditions and results

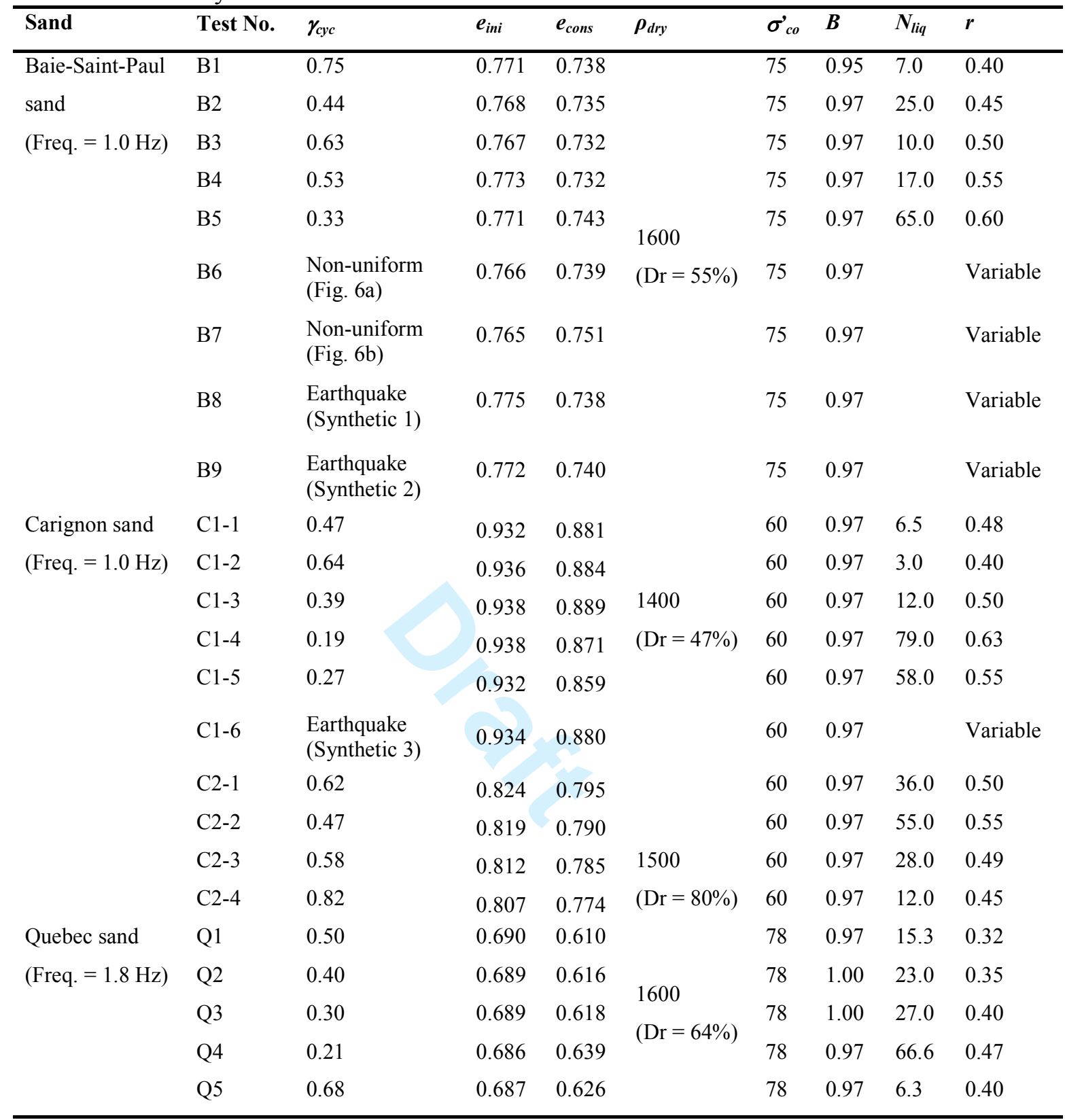

$e_{\text {ini }}$ : initial void ratio before consolidation.

$e_{\text {cons }}$ : final void ratio after consolidation.

$\rho$ : mass density of the soil $\left(\mathrm{kg} / \mathrm{m}^{3}\right)$.

$\sigma_{c o}^{\prime}$ : initial effective confining pressure $(\mathrm{kPa})$.

$B$ : Skempton's pore pressure parameter.

$N_{l i q}:$ number of cycles required to trigger liquefaction.

$r$ : material parameter. 
Table 3a: Summary of computing procedure of $N_{e q \gamma}$ for B6.

\begin{tabular}{|c|c|c|c|c|c|}
\hline$\gamma_{r e f}$ & $N_{\text {liq-ref }}$ & $r_{r e f}$ & $\begin{array}{l}N_{e q \gamma} \\
(\mathbf{R}-\mathbf{N})\end{array}$ & $\begin{array}{l}N_{e q \gamma} \\
(\mathbf{P}-\mathbf{M})\end{array}$ & $\begin{array}{l}N_{e q \gamma} \\
\text { (Fig. 10a) }\end{array}$ \\
\hline 0.330 & 65 & 0.601 & 28.5 & 28.6 & 29 \\
\hline 0.525 & 17 & 0.505 & 6.8 & 8 & 6.5 \\
\hline 0.750 & 7 & 0.442 & 2.3 & 3 & 2.8 \\
\hline
\end{tabular}

Table 3b: Summary of computing procedure of $N_{\text {eqy }}$ for Synthetic 1 (B8).

\begin{tabular}{|c|c|c|c|c|c|}
\hline$\gamma_{r e f}$ & $N_{\text {liq-ref }}$ & $\boldsymbol{r}_{r e f}$ & $\begin{array}{l}N_{e q \gamma} \\
(\mathbf{R}-\mathbf{N})\end{array}$ & $\begin{array}{l}N_{e q \gamma} \\
(\mathbf{P}-\mathbf{M})\end{array}$ & $\begin{array}{l}N_{e q \gamma} \\
\text { (Fig. 10b) }\end{array}$ \\
\hline 0.330 & 65 & 0.601 & 14.15 & 10.9 & 13.2 \\
\hline 0.525 & 17 & 0.505 & 2.77 & 3.0 & 3.2 \\
\hline 0.750 & 7 & 0.442 & 0.88 & 1.17 & 1. \\
\hline
\end{tabular}

Table 3c: Summary of computing procedure of $N_{e q \gamma}$ for Synthetic 2 (B9).

\begin{tabular}{|c|c|c|c|c|c|}
\hline$\gamma_{r e f}$ & $N_{\text {liq-ref }}$ & $\boldsymbol{r}_{\text {ref }}$ & $\begin{array}{c}N_{e q \gamma} \\
(\mathbf{R}-\mathbf{N})\end{array}$ & $\begin{array}{l}N_{e q \gamma} \\
(\mathbf{P}-\mathbf{M})\end{array}$ & $\begin{array}{l}N_{e q \gamma} \\
\text { (Fig. 10c) }\end{array}$ \\
\hline 0.525 & 17 & 0.505 & 17 & 17 & 17 \\
\hline 0.750 & 7 & 0.442 & 7 & 7 & 7 \\
\hline
\end{tabular}

Table 3d: Summary of computing procedure of $N_{\text {eq }}$ for Synthetic 3 (C1-6).

\begin{tabular}{llllll}
\hline$\gamma_{\text {ref }}$ & $\boldsymbol{N}_{\text {liq-ref }}$ & $\boldsymbol{r}_{\text {ref }}$ & $\begin{array}{c}\boldsymbol{N}_{\text {eqy }} \\
(\mathbf{R}-\mathbf{N})\end{array}$ & $\begin{array}{l}\boldsymbol{N}_{\text {eqy }} \\
(\mathbf{P}-\mathrm{M})\end{array}$ & $\begin{array}{l}\boldsymbol{N}_{\text {eqy }} \\
\text { (Fig. 10d) }\end{array}$ \\
\hline 0.20 & 79 & 0.63 & 6.13 & 10.00 & 6.20 \\
0.27 & 58 & 0.55 & 3.10 & 7.34 & 3.00 \\
\hline
\end{tabular}

